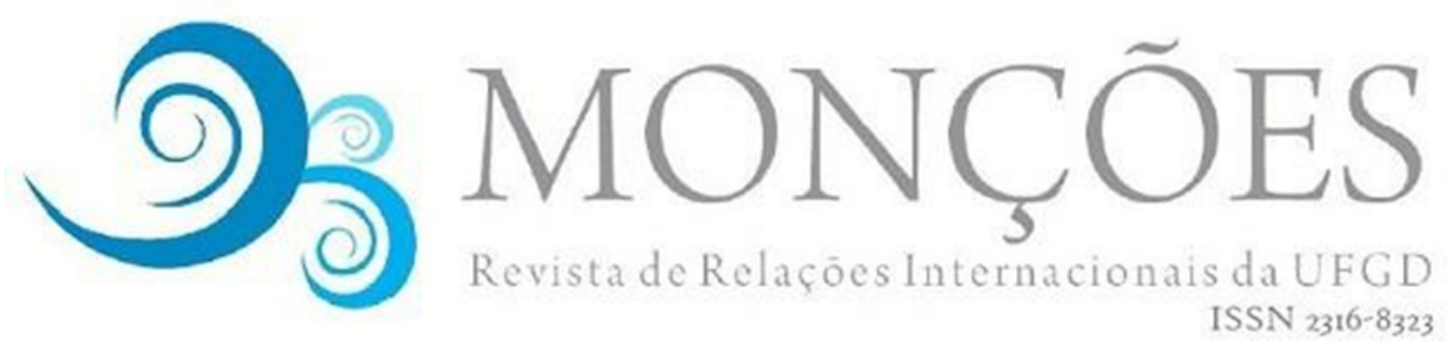

\title{
CRIMEN ORGANIZADO TRANSNACIONAL EN AMÉRICA DEL SUR: UN ANÁLISIS DE LA PRESENCIA Y GOBERNANZA DE ACTORES ARMADOS NO ESTATALES EN LA FRONTERA DE COLOMBIA Y VENEZUELA
}

\author{
MARÍLIA CAROLINA BARBOSA DE SOUZA PIMENTA \\ Fundação Escola de Comércio Álvares Penteado (FECAP-SP). Núcleo de Pesquisa em \\ Relações Internacionais, Universidade de São Paulo (NUPRI-USP) \\ São Paulo, SP, Brasil \\ ORCID: https://orcid.org/0000-0002-6325-9779 \\ profa.marilia.csouza@gmail.com \\ LUIS FERNANDO TREJOS ROSERO \\ Universidad del Norte. Departamento de Ciencia Política y Relaciones Internacionales \\ Centro de Pensamiento UNCaribe \\ Barranquilla-ATL, Colombia. \\ ORCID: http://orcid.org/0000-0003-4988-8576 \\ trejos!@uninorte.edu.co
}

\begin{abstract}
Resumen: Este artículo tiene como objetivo discutir el marco de seguridad en la subregión amazónica, ubicada en la zona sur de la frontera entre Colombia y Venezuela, basado en un análisis de la presencia de actores armados no estatales en los departamentos de Arauca, Vichada y Guainía. Tal análisis nos permite reflexionar sobre los efectos de la baja presencia estatal en esta región, así como sobre los mecanismos informales de gobernanza generados por estos grupos. Cuanto, a los patrones de cooperación entre estos actores, en la dimensión temporal, se camina para alianzas sin tiempo definido, a medida que la operación se mantenga lucrativa y exitosa. Cuanto, al tipo de cooperación, se presentan como parcerías dentro del mismo tipo de actividad, como la cadena de producción, procesamiento y venta de drogas, extracción de minerales, o extorsión. Por fin, el nivel de cooperación se queda entre ocasional y continuo, pero con presencia de disputas, lo que es observado por las periódicas explosiones de violencia como demostración de fuerza por parte de estos actores. Las conclusiones son que los grupos disidentes formados después de los Acuerdos de Paz han aumentado en la región, generando aún más inestabilidad, disputas e inseguridad para las poblaciones locales.
\end{abstract}

Palabras-Clave: Seguridad Regional; Actores Armados no Estatales; América del Sur.

\section{TRANSNATIONAL ORGANIZED CRIME IN SOUTH AMERICA: AN ANALYSIS OF THE PRESENCE AND GOVERNANCE OF NON-STATE ARMED ACTORS ON THE BORDER OF COLOMBIA AND VENEZUELA}

Abstract: This article aims to discuss the regional security framework of Amazonian subregion, localized in the south part of the border between Colombia and Venezuela, based on an analysis of the presence of non-state armed actors in the departments of Arauca, Vichada and Guainia. Such an analysis allows us to reflect on the effects of the low state presence in this region, as well as on the informal governance mechanisms generated by these groups. Regarding the patterns of cooperation between these actors, in the temporal dimension, there

364

Monções: Revista de Relações Internacionais da UFGD, Dourados, v.9. n.17, jan./jun.

Disponível em: http://ojs.ufgd.edu.br/index.php/moncoes

DOI 10.30612/rmufgd.v9i17.10952 
is a move towards alliances without a defined time, as the operation remains profitable and successful. Regarding the type of cooperation, they are presented as partnerships within the same type of activity, such as the chain of production, processing and sale of drugs, extraction of ores, or extortion. Finally, the level of cooperation remains between occasional and continuous, but with the presence of disputes, which can be observed by the periodic explosions of violence as a demonstration of force by these actors. The conclusions are that, in general, dissident groups formed after the Peace Agreements have increased in the region, generating even more instability, disputes and insecurity for local populations.

Keywords: Regional Security; Non-State Armed Actors; South America.

\section{CRIME ORGANIZADO TRANSNACIONAL NA AMÉRICA DO SUL: UMA ANÁLISE DA PRESENÇA E GOVERNANÇA DE ATORES ARMADOS NÃO ESTATAIS NA FRONTEIRA ENTRE A COLÔMBIA E A VENEZUELA}

Resumo: Este artigo tem como objetivo discutir o marco de segurança na subregião amazônica, localizada na parte sul da fronteira entre Colômbia e Venezuela, baseando-se em uma análise da presença de atores armados não estatais nos departamentos de Arauca, Vichada e Guainía. Tal análise nos permite refletir sobre os efeitos da baixa presença estatal nesta região, assim como sobre os mecanismos informais de governança gerados por tais grupos. Quanto aos padrões de cooperação entre tais atores, na dimensão temporal, caminha-se para alianças sem tempo definido, à medida que a operação continue lucrativa e bem-sucedida. Quanto ao tipo de cooperação, elas se apresentam como parcerias dentro de um mesmo tipo de atividade, como cadeia de produção, processamento e comercialização de drogas, extração de minérios ou extorsão. Por fim, o nível de cooperação permanece entre o pontual e o contínuo, porém com presença de disputas, o que pode ser observado pelas explosões periódicas de violência como demonstração de força desses atores. As conclusões são que, em geral, os grupos dissidentes formados depois dos Acordos de Paz aumentaram na região, gerando ainda mais instabilidade, disputas e insegurança para as populações locais.

Palavras-Chave: Segurança Regional; Atores Armados não-Estatais; América do Sul.

\section{TENDENCIAS EN LA SEGURIDAD REGIONAL, ÁREAS NO GOBERNADAS Y GOBERNANZA INFORMAL EN LOS DEPARTAMENTOS DE ARAUCA, VICHADA Y GUAINÍA.}

Este artículo tiene como objetivo reflexionar sobre la situación de seguridad en la zona sur de la frontera entre Colombia y Venezuela, ubicada en el territorio amazónico de ambos Estados ${ }^{1}$. Con el objetivo de ser un artículo de reflexión, se revisaron las dinámicas producidas por la presencia de actores armados no estatales en los departamentos colombianos de Arauca, Vichada y Guainía. Teniendo como

\footnotetext{
${ }^{1}$ La frontera entre Colombia y Venezuela tiene una extensión de $2.219 \mathrm{~km}$ lineales y no es homogénea en términos sociales, económicos y culturales, por lo que debe abordarse desde enfoques diferenciados. Es por eso que Rodríguez, De la Puente y Trejos (2018) proponen dividir la frontera en tres zonas: Norte (Guajira y Cesar), Centro (Boyacá y Norte de Santander) y Sur (Arauca, Vichada y Guainía). Esta división se basa en la ubicación territorial de las macroestructuras insurgentes y paramilitares que operaban y aún operan en ellos.
}

Monções: Revista de Relações Internacionais da UFGD, Dourados, v.9. n.17, jan./jun. 
contexto la baja presencia estatal en esta subregión colombiana, así como los mecanismos informales de gobernanza criminal generados por los grupos armados no estatales, las conclusiones son que, en general, los grupos disidentes que se marginaron durante y después de las negociaciones de los Acuerdos de Paz con las Fuerzas Armadas Revolucionarias de Colombia - Ejército del Pueblo (FARC-EP) han crecido en la región y han logrado coordinar, con empleo de violencia, su actividad criminal con otros actores armados.

El presente diseño de investigación se presenta como un trabajo de reflexión, por medio de una revisión bibliográfica, en torno al tema general del espectro de seguridad de América del Sur. Con base en esto, buscamos reflexionar sobre este tema a la luz de los conceptos de (I) áreas no gobernadas y (II) la gobernanza híbrida o alternativa, aplicados a la subregión de la frontera sur entre Colombia y Venezuela². Con este fin, el artículo tendrá la siguiente pregunta como un problema de investigación: ¿cómo es la dinámica de violencia de los grupos disidentes de las FARC-EP en la subregión de la frontera sur entre Colombia y Venezuela?

En el marco de los conflictos actuales y su reflejo en las discusiones académicas, es necesario evaluar sus impactos con respecto a la seguridad subregional, en función de las amenazas que afectan a América del Sur, y se vuelve relevante a medida que aumenta la percepción, tanto en el ámbito académico como en el político, de que el desarrollo genera seguridad y que las áreas subdesarrolladas o en vías de desarrollo, con focos de pobreza y espacios con baja presencia estatal, pueden generar inseguridad, especialmente frente a flujos ilícitos, nuevas guerras y nuevas amenazas (FRANÇOIS; SUD, 2006).

En las últimas dos décadas y media, ha habido una producción robusta de trabajos teóricos, principalmente relacionados con el fenómeno de las comunidades de "paz larga", paz negativa, paz híbrida y seguridad en América del Sur (HOLSTI, 1996; KACOWICZ, 1998, 2005; MARES, 2001, 2012; BUZAN; WEAVER, 1998, 2003, 2009; MILLER, 2007; OELSNER, 2007; MERKE, 2015; BATTAGLINO, 2012).

\footnotetext{
${ }^{2}$ Esta investigación se destina sólo al análisis del territorio Colombiano y sus departamentos fronterizos al sur con Venezuela, y no al territorio Venezolano, por el momento.
} 
Otra narrativa importante sobre la construcción de la paz en América Latina, que hace una superposición conceptual con Holsti (1996) y Kacowicz $(1998,2005)$, es la de Jorge Domínguez (2007), según la cual América del Sur se estaría moviendo hacia una comunidad de seguridad pluralista, principalmente los países del Cono Sur, pero tales características están ausentes o tienen fallas en el Norte de América del Sur, en las subregiones Amazónica y Andina.

Dentro de este contexto, uno de los aspectos más llamativos, tanto en la literatura actual como en los discursos pronunciados por los responsables políticos, son las llamadas áreas no gobernadas, o espacios sin gobierno, que parecen afectar a las regiones de bajo desarrollo y, en algunos casos, están relacionados con Estados frágiles que contienen espacios de vulnerabilidad.

De hecho, la idea del lado oscuro de la sociedad internacional está inspirada en el trabajo de Tickner, García y Arreaza (2011), quienes observaron el caso de actores violentos no estatales en América del Sur, desde el conflicto colombiano y el narcotráfico, y enfatiza este lado oscuro de la sociedad civil sudamericana desde una perspectiva crítica. El análisis de Tickner, García y Arreaza destaca la compleja relación de las transacciones nacionales e internacionales que se ha desarrollado entre los actores armados no estatales en relación con la cadena del narcotráfico, que constituiría el principal combustible para la permanencia del negocio, frente a los programas de erradicación del estado, aprensión, militarización, entre otros. (TICKNER; GARCÍA; ARREAZA, 2011, p. 414).

Sin aceptar ese vínculo automático entre dichos parámetros, el objetivo principal de esta investigación es tratar de analizar este fenómeno, teniendo en cuenta que América del Sur es una región identificada como un lugar de desarrollo para el crimen organizado transnacional, o como zonas estratégicas para los tránsitos ilícitos (ZEETIs), en razón de sus aspectos estructurales, como señaló Pimenta (2016).

Como señala Clunan (2010, p. 5), el término "áreas no gobernadas" se refiere a un tipo de amenaza aún poco conocida, capaz de poner en peligro el sistema internacional y a las cuales los Estados en general están poco preparados para hacer frente. La autora también reconoce que el concepto se ha relacionado, especialmente 
en las esferas políticas, con estados frágiles o estados fallidos, y que, al final, ha justificado una serie de intervenciones internacionales.

La autora comprende, y esto tiende a ser la percepción desarrollada aquí, que los espacios "no gobernados", así como las áreas urbanas o rurales en disputa, o incluso los espacios virtuales o financieros, pueden convertirse en áreas de refugio para los actores ilegales y así organizar, capacitar, reclutar, planificar, buscar fondos, comunicarse y mantener tales prácticas de manera razonablemente segura y regular.

Por lo tanto, es necesario investigar los espacios no gobernados no solo desde la perspectiva de la falta de gobernanza y, sobre todo, la ausencia del estado, sino tratar de distanciarnos de los parámetros que están demasiado centrados en el Estado, para examinar la interacción entre los actores criminales y en qué medida pueden ser el resultado de las políticas perversas y/o corruptas de los Estados. Así, al comprender que la ausencia de Estado no es sinónimo de caos o anarquía, se pueden determinar cuáles son los tipos de gobernanza alternativa que surgen en ciertos lugares (VILLA; PIMENTA, 2019).

Autores como O’Donnell (1993), Bartolomé (2003), Cirino y Elizondo (2003) y Cirino (2002) las definen como aquellos espacios en que actores no estatales ligados a dinámicas y redes de ilegalidad local e internacional logran adquirir tantos recursos (humanos y materiales) e influencia que se imponen a las instituciones estatales, ya sea por su débil presencia o por su total ausencia.

En este sentido, Cirino y Elizondo (2003) plantean tres tipos de factores que facilitan la aparición y sostenimiento de las áreas sin ley: (i) Políticas. Estas se relacionan con una débil institucionalidad estatal, lo que produce una sostenida incapacidad para mantener los monopolios legítimos de la violencia, la administración de justicia y el recaudo tributario, teniendo como telón de fondo la presencia de agentes estatales con elevados niveles de corrupción; (ii) Geográficas. Las áreas de frontera, por su difícil acceso por la presencia de ciertas condiciones geográficas y falta de infraestructura vial y de comunicaciones, no han sido articuladas a los centros de producción. Este aislamiento las convierte en espacios propicios para el establecimiento de grupos al margen de la ley relacionados con el crimen internacional; (iii) Económicas. Al instalar zonas francas en estas áreas se amplían las 
capacidades operativas de los actores ilegales, debido a las ganancias económicas producidas por rentas ilícitas como el narcotráfico, el lavado de activos y el contrabando generan los recursos necesarios para el desarrollo de sus actividades. Un ejemplo es la Ciudad de Maicao en la Guajira Colombiana (TREJOS, 2015).

En estas áreas se configura lo que se denomina una "ingobernabilidad hobbesiana", definida como una ruptura continua del tejido social en un contexto de violencia y criminalidad ininterrumpida, en territorios en los que los agentes estatales no tienen los recursos necesarios para imponer las leyes de manera efectiva, de ahí que el mantenimiento del orden público y la prestación de seguridad colectiva son inciertos (O'DONNEL, 1993).

En la literatura relativamente de los finales de los años 1990, se ha hablado de las "áreas grises". Este concepto fue utilizado para describir aquellos territorios en los que se presentan características similares a las que se encuentran en las áreas sin ley, como la presencia de organizaciones político-criminales, espacios que sirven de retaguardia y santuario de grupos ilegales y zonas en las que el Estado es incapaz de imponer su autoridad (O'DONNEL, 1993).

Para Trejos (2014), los territorios desgobernados surgen de una deficiente o nula interacción de dos variables, a saber: espacio referido al territorio y el porcentaje de presencia efectiva o control que el Estado ejerce sobre el mismo. En este caso, se entiende presencia estatal como el cumplimiento permanente y efectivo de las obligaciones primarias del Estado, tales como: administrar justicia, brindar seguridad, recaudar tributos y garantizar la prestación y el acceso a servicios públicos básicos a todos sus ciudadanos. Aunque esta definición se considere como poco técnica, lo que se pretende resaltar es que la presencia del Estado no sólo debe limitarse a la instalación física de sus instituciones, sino que además estas instituciones deben prestar los servicios para los cuales fueron concebidas (TREJOS, 2014).

Nuestro marco teórico establece un nexo entre los actores armados no estatales y el alcance geográfico, el acceso a la financiación, los recursos, el papel de la violencia, las interacciones entre los actores y las autoridades estatales. Nos centramos en la "gobernanza más allá de los gobiernos", o incluso en modos 
informales de gobernanza que surgen en espacios de presencia estatal limitada y que operan "fuera del control del gobierno".

Con respecto a la gobernanza en estos espacios, los "mapas" de las llamadas áreas no gobernadas materializan lo que Rosenau (1990) llamó la existencia de dos mundos, uno centrado en el estado y uno multicéntrico, que están en una colisión creciente, donde, muchas veces, las acciones estatales no son suficientes para frenar las aspiraciones de tipo no estatal, que se han fortalecido cada vez más.

Al observar esta preocupación con los estándares de autoridad y gobierno, Rosenau y Czempiel (1992) diagnostican los cambios que ocurrirían en dichos estándares a lo largo de los años 1990, y llaman la atención sobre el concepto de hegemonía, que, según los autores, estaría disminuyendo y los problemas relacionados con las fronteras, los "muros" y la autoridad estatal darían lugar a búsquedas alternativas de gobernanza y autoridad, y, por esta razón, sería urgente pensar en las alternativas viables y deseables de gobernanza y autoridad que los actores sociales querían construir, ya que estos podrían dar paso a alternativas indeseables, en vista de la alta volatilidad e intensificación de los cambios en curso.

Se sabe que la mayoría de los llamados espacios no gobernados son, en realidad, espacios gobernados alternativamente e/o híbridos. Los grupos armados no estatales establecen nuevos patrones de gobernanza: en este contexto, el establecimiento de estándares de gobernanza ya no es dominio exclusivo de los estados o gobiernos. Cuando los estados débiles no pueden crear o mantener la lealtad de sus poblaciones, individuos y grupos, estos últimos generalmente recurren o desarrollan patrones alternativos de afiliación (VILLA; PIMENTA, 2019)

Por lo tanto, la justificación de tales grupos sería esencialmente reducir los costos operativos, aprovechando los canales ya obtenidos y dominados por diferentes grupos. El concepto de ganancias absolutas aquí puede emplearse, ya que la destrucción mutua y la competitividad perjudicial causarían el sufrimiento de todas las organizaciones. Sin embargo, es importante mostrar que los patrones de cooperación pueden ser frágiles y flexibles y variar entre ellos, según ciertos aspectos. Son ellos, conforme a Williams (2005, p. 117): 
(i) Tiempo: las relaciones de cooperación pueden variar de una sola acción a una cooperación a largo plazo;

(ii) Tipo de actividad: la cooperación puede llevarse a cabo dentro de la misma cadena de actividades, como la producción, la retirada y la distribución de drogas, o puede tomar la forma de intercambios, como drogas por armas, o incluso en forma de prestación de servicios específicos, como transporte, lavado de dinero o corrupción, entre otros;

(iii) Nivel de cooperación: la cooperación puede ser ocasional, continua o incluso crucial para los grupos criminales.

Cabe señalar que, eventualmente, tales lazos pueden romperse y, en el caso de organizaciones criminales, no existe un estado de derecho contractual para resolver disputas entre las partes. Generalmente, cuando hay competencia o disputas, causadas por desconfianza, o incluso por acciones para excluir a algún grupo de los negocios, la violencia es, en la mayoría de los casos, un recurso utilizado. Las relaciones de confianza, la base para la cooperación entre tales grupos, son de hecho frágiles, ya que se sabe que tales grupos quieren, a toda costa, reducir los costos de transacción, incluso si, para ello, tienen que: "eliminar algún grupo intermedio de transacción, incluso si inicialmente abrió el mercado en cuestión" (WILLIAMS, 2005, p. 127).

Annete Idler (2012, p. 68, 69), inspirada en Phil Williams (2010), señala que los acuerdos firmados entre los Actores Violentos no Estatales (VNSAs) en las regiones fronterizas de Colombia, específicamente en las fronteras con Ecuador y Venezuela, mostraron que existen al menos siete categorías principales de interacción entre dichos grupos, ya sean:

(i) Combate violento;

(ii) Ventas en efectivo y acuerdos de intercambio;

(iii) Alianzas tácticas;

(iv) Subcontratos;

(v) Relaciones logísticas complementarias;

(vi) Alianzas estratégicas;

(vii) Convivencia pacífica. 
Por lo tanto, se analizará, para aplicar la teoría aquí examinada, con sus límites y potencialidades, Colombia y su realidad contradictoria per se, donde, por un lado, hay un estado "fuerte" y militarizado, una tendencia que se ha intensificado en los últimos 20 años a través del Plan Colombia y sus diversos programas. Por otro lado, se ha evidenciado un Estado que no ha resuelto efectivamente los problemas históricos de distribución de la tierra y que no ha implementado un plan integral de desarrollo socioeconómico, creando así focos de pobreza y subdesarrollo y fuentes alternativas de gobernanza, que a menudo coinciden con las zonas rurales y fronterizas del país, donde subyace la acción de los grupos armados insurgentes y paramilitares y la acción de los grupos de narcotraficantes. (PIMENTA, 2017)

Este escenario dual ha sido una tendencia común en otros estados de América Latina, donde, por un lado, hay una mano fuerte del estado militarizado y, por otro lado, la ausencia del estado y de las agencias y programas para crear un entorno de estabilidad y desarrollo de estos territorios, que, por varias razones, pueden volverse estratégicos para la proliferación del crimen organizado transnacional y para la acción de los grupos armados ilegales. Por esta razón, elegimos analizar el área fronteriza colombiana con Venezuela, ya que este es un país que, desde 1998, ha sido testigo del surgimiento de procesos de transformación económica y social, además de la centralización política, y ha estado marcado por el discurso de fortalecimiento de la presencia estatal en el territorio y la realización de reformas estructurales.

Dicho esto, cuestiones tradicionales como las disputas territoriales y la demarcación de las fronteras coexisten con luchas y violencia en las fronteras, especialmente aquellas que involucran disputas sobre los recursos naturales asociados con la pesca, la exploración petrolera, la extracción de oro, las autonomías indígenas; se superpusieron a cuestiones relacionadas con el tráfico de drogas, el tráfico ilícito de armas y el contrabando, así como la presencia y las disputas entre grupos ilegales generan aún más tensiones en las zonas fronterizas de la región. (PIMENTA, 2017).

David Mares (2012) también afirma que aspectos internos como la inestabilidad institucional, la violencia causada por el crimen organizado y las pandillas, así como la desigualdad económica, son aspectos centrales para la formación del marco de 
seguridad de la región. En este sentido, el autor destaca el doble carácter del "papel decreciente del Estado" en la región, como se observa en:

\begin{abstract}
mientras que los gobiernos obtuvieron autoridad a través de reformas constitucionales, reveses legislativos y decretos administrativos, con el objetivo de aliviar las restricciones institucionales a su poder y buscar soluciones consensuadas. (...) Estos cambios políticos, significativos en varios países, plantean preocupaciones sobre el futuro de la democracia y también regulan que es apropiado usar niveles crecientes de poder estatal para enfrentar amenazas que desafían la resolución por medios normales (MARES, 2012, p. 605).
\end{abstract}

El marco de seguridad en la región, desde la percepción de Mares, se refiere a un Complejo de Seguridad Regional (usando el concepto creado por Buzan y Weaver) con una arquitectura "nueva y flexible" que se enfoca más en garantizar la soberanía nacional (precepto histórico) y democracia (valor reciente) en la región, en detrimento de prevenir la militarización de los conflictos interestatales, lo que resalta nuestra percepción de que la Zona de Paz aún no se ha consolidado de manera consistente en la región.

Figura 1 - Mapa de los departamentos de Arauca, Vichada y Guainía.

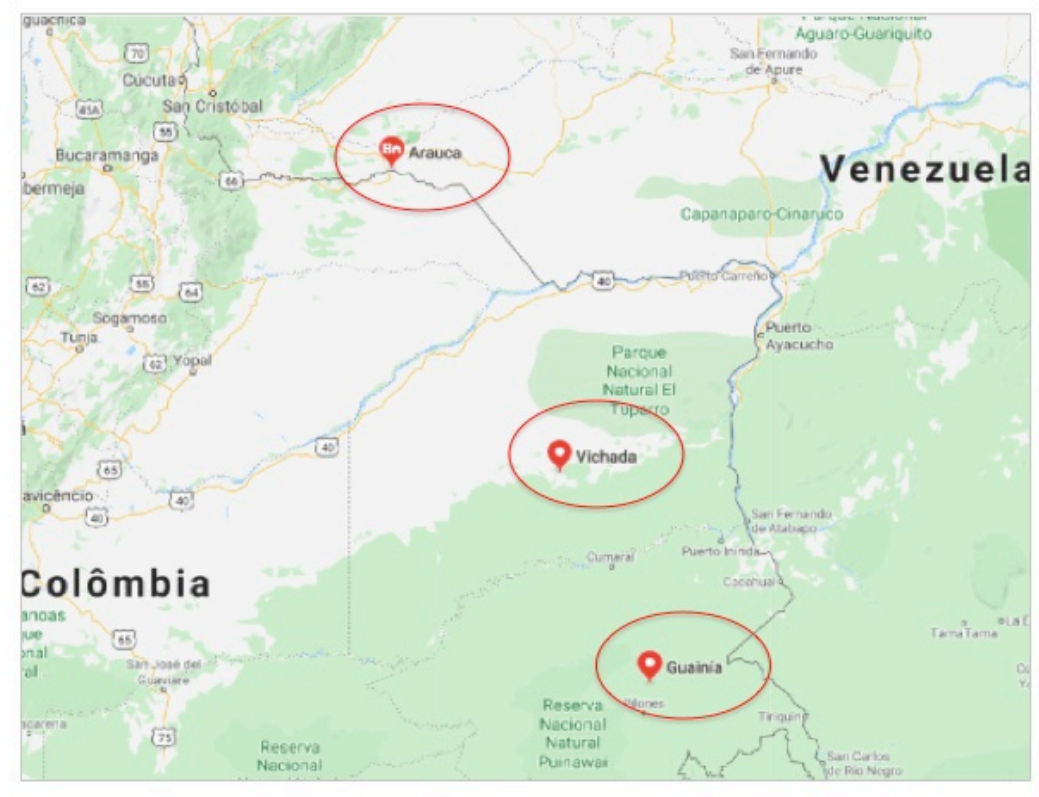

Fuente: Google Maps. Disponible en:

https://www.google.com/maps/search/mapa+arauca+guainia+vichada/@4.1291648,71.2101597,7z/data=!3m1!4b1. Acceso en: 15.11.2019. 
El Departamento de Arauca está situado en el extremo norte de la región de la Orinoquia Colombiana, con una superficie de $23.818 \mathrm{Km}^{2}$, limitando al norte con el río Arauca, límite natural con la República Bolivariana de Venezuela, por el oriente con la República Bolivariana de Venezuela y al sur con los ríos Meta y Casanare, que lo separan de los Departamentos del Vichada y Casanare y por el occidente con el Departamento de Boyacá.

En el caso del Vichada, este fue elevado a la categoría de departamento especial el 4 de Julio de 1991 por la Asamblea Nacional Constituyente, alcanzando sus funciones político-administrativas como departamento en 1995. Su superficie es de $105.947 \mathrm{~km}^{2}$ y se ubica en la región oriental de Colombia, en la margen derecha del río Meta y en la izquierda del Orinoco y en la denominada altillanura. El Vichada cuenta con un relieve conformado por amplías y extensas llanuras pertenecientes a los Llanos Orientales colombianos, que van desde el piedemonte de la cordillera Oriental hasta la República de Venezuela, sobre la cuenca del río Orinoco. Limita al norte con el departamento de Arauca y la República Bolivariana de Venezuela. Al oriente con Venezuela, al sur con el departamento del Guainía y el departamento del Guaviare. Por último, al occidente con el departamento del Meta y el del Casanare (GOBERNACIÓN DEL VICHADA, 2017).

Por su parte, el Guainía fue creado como departamento el 4 de julio de 1991. Guainía se ubica en el oriente del país, más precisamente en la región de la Amazonía y tiene una superficie de $70.691 \mathrm{~km}^{2}$, lo que representa el $6,2 \%$ de todo el territorio nacional. Al norte limita con el río Guainía, que es límite natural con el departamento del Vichada; por el Oriente con los ríos Atabapo, Guainía y Negro, que lo separan de la República de Venezuela; por el Sur con la República de Brasil y por el Oeste con los departamentos del Vaupés, Guaviare y Vichada (GOBERNACIÓN DEL GUAINÍA, 2018).

ACTORES ARMADOS, CONFLICTO Y CONTEXTO PREVIO A LA FIRMA DEL ACUERDO

A modo de contexto se hace necesario conocer la relación de las entonces FARC-EP con la coca, los cultivadores de coca y los narcotraficantes en el sur del 
país, evidenciando que esta interacción ha sido dinámica y cambiante. De su férrea oposición inicial a la siembra de la hoja de coca en 1977, pasan a su aceptación y regulación en 1979 y en 1982 inician el cobro de impuestos a los comerciantes de pasta de coca, a los laboratorios de producción de cocaína y a los vuelos de carga.

En los noventa dan inicio a la regulación policiva del comportamiento de los narcotraficantes y miembros de los laboratorios de producción de clorhidrato de cocaína. En este sentido, el entonces comandante, durante los fallidos diálogos del Caguán manifestaba:

El que compraba y vivía en la zona, se sometía a las normas de nosotros: no cargar armas, máximo un revolver, jamás una nueve milímetros, no traer gente sin saber uno quién es, y si la traía, tenía que responder por lo que él hiciera en la zona (FERRO; PAREDES, 2002, p. 99).

En 1996 promovieron y organizaron las primeras marchas cocaleras en contra de la fumigación aérea; desde 1999 inician un proceso de restricción en el ingreso de compradores de pasta de coca para evitar infiltraciones paramilitares y en paralelo los paramilitares empiezan la competencia por la compra de los territorios de presencia guerrillera. En el año 2000 se inicia la comercialización directa en Colombia y sus fronteras de la pasta de coca por parte de las FARC-EP (TREJOS, 2015).

El control y regulación de la coca en sus territorios también les era funcional y orgánico y ahora a las disidencias también lo son, ya que:

\begin{abstract}
Aunque parezca paradójico, el control de la economía de la coca le representa ventajas a la guerrilla en términos de su crecimiento, incluso cuando hay una fuerte reducción de los precios. Las crisis periódicas de la coca también favorecen a la guerrilla porque ingresar a sus filas se convierte casi en la única alternativa frente a la falta generalizada de oportunidades laborales (FERRO; PAREDES, 2002, p. 100).
\end{abstract}

La realidad indicaba que las FARC-EP habrían tenido dificultades reales para haber escalado la guerra que libraban contra el Estado colombiano sin los cuantiosos recursos financieros que obtenían por medio de un particular sistema de tributación coactiva (gramaje) que impusieron en las zonas de cultivos y procesamiento de la hoja de coca bajo su control. 
Lo que debe tenerse claro es que si bien las FARC-EP se relacionaron en su momento activamente con el narcotráfico, nunca controlaron toda la cadena de producción y distribución de la cocaína. En muchos casos su control llegó hasta la fase de contacto con quienes intermedian y transportan la cocaína hacia los mercados de consumo final. El vínculo y dependencia económica de muchas de sus estructuras con esta actividad ilegal los obligaba a entablar contactos comerciales con narcotraficantes, como quedó demostrado en abril de 2001 cuando en el desarrollo de la "Operación Gato Negro", ejecutada por el Ejército colombiano en el departamento del Guaviare en contra del frente 16 de las FARC-EP, fue capturado el narcotraficante brasilero Luis Da Costa, alias "Fernandinho" (TREJOS, 2015).

En la actualidad, la situación relatada anteriormente se reproduce con las disidencias, especialmente las ubicadas en el oriente colombiano en la zona de frontera con Venezuela. En estas regiones las disidencias de las FARC-EP controlan algunas rutas por las que sale la cocaína hacia los países vecinos, pero los corredores de ingreso a los grandes mercados de consumidores están en manos de los narcotraficantes y carteles de alto perfil.

El siguiente texto sirve para entender la dinámica que se presentaba dentro de las estructuras de las FARC-EP y que sucede en la actualidad con sus disidencias con respecto al narcotráfico:

\begin{abstract}
Es importante señalar que no todos los frentes viven de la cadena productiva del narcotráfico y que algunos nunca lo han hecho. La presencia de los recursos del narcotráfico establece una odiosa diferencia entre frentes ricos, en expansión, con frentes pobres y dependientes. Los primeros se fortifican militarmente, pero se debilitan políticamente. Los segundos progresan políticamente, pero son débiles militarmente (ÁVILA, 2012, p. 240).
\end{abstract}

En Arauca la insurgencia armada hace presencia desde la década de 1970 y son los actores armados ilegales con mayores dinámicas político-militares. La primera organización armada que hizo presencia en este territorio fue el Ejército de Liberación Nacional (ELN) con el Frente Domingo Lain, a principios de la década de los setenta del siglo anterior, y este hasta la actualidad es el actor armado hegemónico (MISIÓN DE OBSERVACIÓN ELECTORAL MOE, 2008; OBSERVATORIO DEL PROGRAMA PRESIDENCIAL DE DDHH Y DIH, 2009). Parte del crecimiento de esta estructura 
armada se debe, por un lado, a la construcción de un aparato militar ofensivo y a la creación de estrechos vínculos con la población local, esto sobre la base de acceso a una estable fuente de finanzas derivadas de la extorsión a empresas petroleras.

En cuanto a las FARC-EP, esta hizo incursiones en el departamento desde los años setenta, pero su presentación formal se dio en 1980 con la toma militar del municipio de Fortul y la creación del Frente 10 o Guadalupe Salcedo (FUNDACIÓN IDEAS PARA LA PAZ, 2014; OBSERVATORIO DEL PROGRAMA PRESIDENCIAL DE DH Y DIH, 2008).

A principios de 2000, llega al departamento el Bloque Vencedores de Arauca (BVA) de las Autodefensas Unidas de Colombia (AUC) y logra cierto control de la Sabana, y algunas áreas de la capital del departamento y el municipio de Tame. El BVA estuvo respaldado por la fuerza pública y política local (FUNDACIÓN IDEAS PARA LA PAZ, 2014). Esta estructura fue creada por la Casa Castaño, que posteriormente vendió la franquicia del grupo a los narcotraficantes Miguel y Víctor Mejía Múnera (Los Mellizos).

En los casos del Vichada y el Guainía, llegaron las FARC-EP por medio del Frente 16. Este frente guerrillero nació en 1983 como resultado del desdoblamiento de los frentes 1,7 y 10 , con el fin de obtener y ampliar finanzas por medio de la regulación de la compra y venta de pasta de coca y cocaína. Además de eso, por operar en zona de frontera, debía establecer contactos internacionales con fines de comerciar las drogas y el ingreso de armas. Por la cantidad de recursos que obtenía por efectos del narcotráfico, este frente logró convertirse en una de las principales fuentes de finanzas de las FARC-EP.

En el Guainía, las FARC-EP tenían el Frente Acacio Medina, cuya estructura tiene una historia distinta, según Álvarez, Pardo y Cajiao (2018). En sus inicios fue proyectada como un componente de su dispositivo fronterizo por la necesidad de aumentar la presencia de las FARC-EP en los países vecinos con el fin de asegurar la compra e ingreso de armas y la comercialización de la coca, según lo planeado en 1993 durante la realización de su Octava Conferencia.

El frente se conformó entre los años 2007 y 2009, en el marco de una estrategia de repliegue y contención. Repliegue como medida de seguridad para los guerrilleros 
que no podían combatir por edad o salud y requerían algún tratamiento médico especializado en Venezuela. La contención se refería a un eventual revés del Plan Renacer, lanzado en $2009^{3}$, y se debe recordar que en el año 2009 en esta región se presentaba la tasa más alta de concentración de cultivos de coca por vereda, de ahí que las FARC consolidaran su presencia en ese territorio con el fin de sostener una importante parte de sus finanzas.

En esta región también hacia (y hace) presencia el Frente 1 (Armando Ríos), que llegó a ser una estructura emblemática dentro de las FARC-EP, ya que su nacimiento se vincula al nacimiento de esa organización armada en 1965. En esa época no eran llamados frentes, sino destacamentos del Bloque Sur. A inicios de la década de los setenta del siglo pasado, se convierte en el Frente 1, ubicado inicialmente en el departamento de Caquetá, territorio en el que realizó trabajo político, y años después se traslada a los departamentos de Guainía y Vaupés, logrando con el tiempo consolidarse territorialmente y construir una importante base social (ÁLVAREZ; PARDO; CAJIAO, 2018).

En la década de los ochenta, por medio de sus desdoblamientos, dio origen a los Frentes 7, 16 y 27. Posteriormente, se mueve hacia la frontera con Brasil, en los límites del departamento de Vaupés, con el fin de regular la explotación ilegal del oro y consolidar su presencia en la frontera. Su relación con el narcotráfico en un principio se reducía a regular el mercado de compra y venta de hoja de coca y controlar las rutas fluviales para trasladar, mover y sacar la pasta de coca hasta los cristalizaderos. Posteriormente intervendría directamente en las fases de siembra y procesamiento (ÁLVAREZ; PARDO; CAJIAO, 2018).

Las tres estructuras señaladas anteriormente pertenecieron al desmovilizado Bloque Oriental de las FARC-EP y dentro de esta macroestructura guerrillera fueron

\footnotetext{
${ }^{3}$ EI Plan Renacer de las FARC-EP fue una estrategia para aumentar sus ataques con el uso de minas, explosivos y francotiradores, en un intento de evitar una derrota militar y recuperar el espacio político perdido con el gobierno. Para esto, el entonces primer comandante de esta organización armada, "Alfonso Cano ordenó disponer de US\$6 millones del fondo del secretariado para adquirir material de guerra y comunicaciones, aumentar las minas antipersonas y los cursos de explosivistas, fortalecer la táctica de francotiradores ordenada desde la Octava Conferencia, infiltrar al Ejército con falsos soldados profesionales y lograr la negociación de misiles para contrarrestar el poderío aéreo de las Fuerzas Militares" (ELESPECTADOR.com, 2014).
} 
desplegadas en un área que conecta la Altillanura y las fronteras con Venezuela y Brasil, atravesando los departamentos del Vichada y Guainía. En este territorio, la minería ilegal hace parte del portafolio de rentas ilícitas que regulaban las FARC-EP y aún controlan sus disidencias en la actualidad (ÁLVAREZ; PARDO; CAJIAO, 2018)

En el caso de los grupos paramilitares, estos incursionan en el departamento del Vichada en la segunda mitad de la década de los noventa por medio del Bloque Centauros (BC) de las AUC, con el fin de disputarle a las FARC-EP los cultivos de coca. Posteriormente, las Autodefensas del Meta y Vichada (AMV) son absorbidas por las estructuras del $\mathrm{BC}$, que logran controlar un porcentaje importante de los cultivos ilícitos en Cumaribo, al sur del río Vichada (OBSERVATORIO DEL PROGRAMA PRESIDENCIAL DE DH Y DIH, 2008).

Con la muerte de Miguel Arroyave, comandante del BC de las AUC, en septiembre de 2004, esta estructura se fracturó en tres grupos, los cuales fueron liderados por Jorge Pirabán, alias "Jorge Pirata", otro por Pedro Oliverio Guerrero, alias "Cuchillo" y uno en el que se ubicó el grueso de los combatientes del BC, comandado por alias "Mauricio", quien se desmovilizó en septiembre de 2005 (ELTIEMPO.COM, 2004).

En paralelo, el Bloque Central Bolívar de las AUC, por medio del Frente Vichada comandado por Carlos Mario Jiménez, alias "Macaco", se ubicó en el municipio de Cumaribo, con el objetivo de avanzar hacia el norte del departamento, cruzando los ríos Vichada y Tomo, hasta llegar a Santa Rosalía. Su objetivo era capturar las rentas ilícitas desplegadas en el territorio, controlar las rutas fluviales y las zonas con alto valor estratégico para el desarrollo de proyectos agroindustriales de cultivo de palma y extracción de materiales para biocombustibles (OBSERVATORIO DEL PROGRAMA PRESIDENCIAL DE DH Y DIH, 2008).

\section{DINÁMICAS CRIMINALES EN EL POSACUERDO}


En este punto es importante destacar que estos dos últimos departamentos (Vichada y Guainía) ${ }^{4}$ tienen la particularidad de que son grandes en cuanto a sus extensiones territoriales pero son muy poco habitados; gran parte de su territorio es selvático; son atravesados por redes fluviales; y el despliegue de las Fuerzas Militares es reducido y se concentra en las capitales departamentales, lo que en la práctica los convierte en espacios vacíos propicios para el desarrollo de rentas ilícitas como el narcotráfico y la minería ilegal que son reguladas por actores armados.

Tabla 1 - Presencia y Control de grupos armados no estatales en la frontera sur entre Colombia y Venezuela

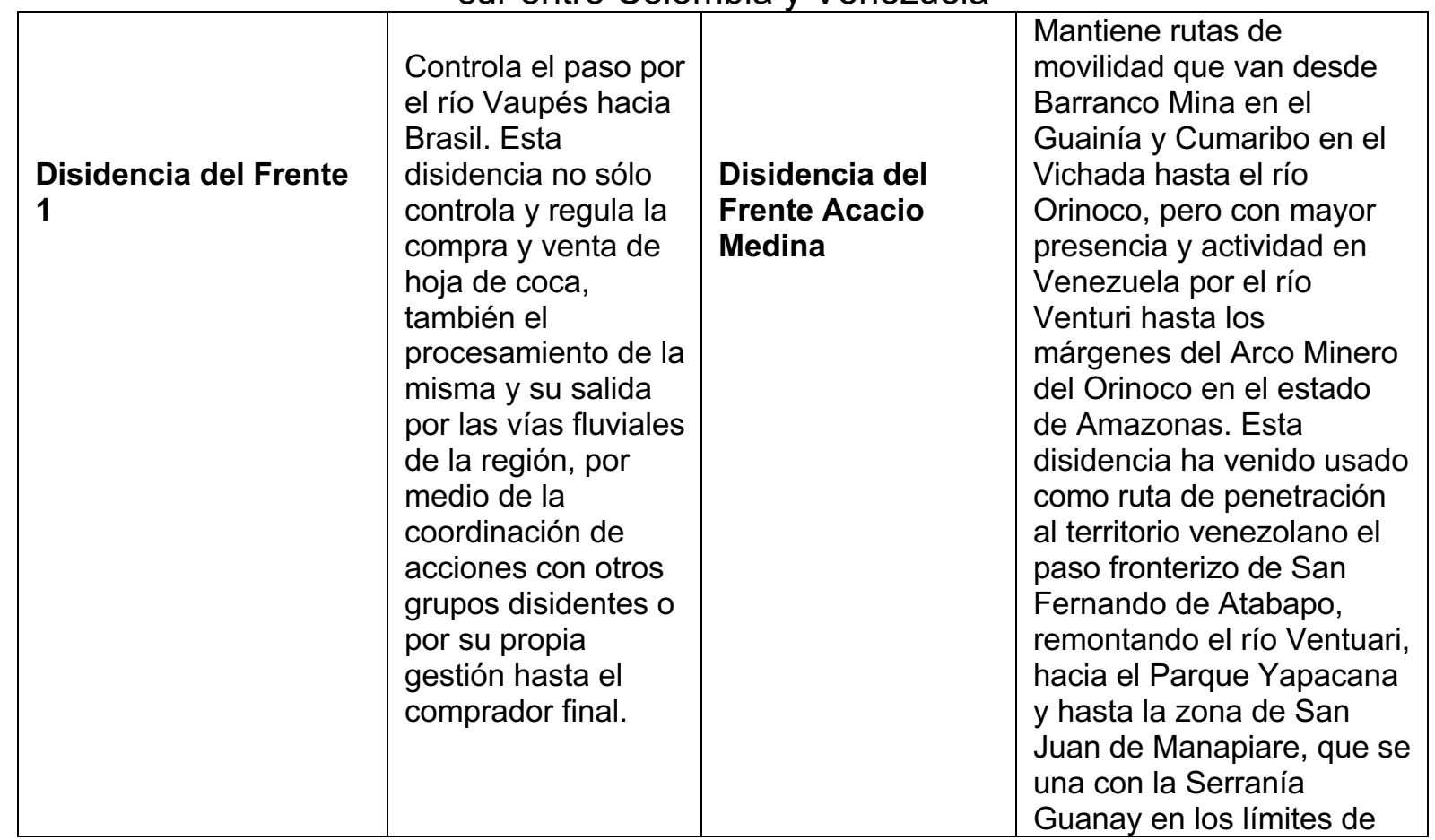

\footnotetext{
${ }^{4}$ En el Vichada la densidad poblacional es de 0,73 habitantes por kilómetro cuadrado y en el Guainía es de 0,54 habitantes por $\mathrm{km}^{2}$. A la capital de Guainía (Puerto Inírida) solo se llega desde Bogotá por vía fluvial a través del río Guaviare o por avión. Al respecto véase la siguiente crónica: https://www.eltiempo.com/archivo/documento/CMS-15310715. En el caso del Vichada, estas son las opciones de llegada desde Bogotá: "Ruta 1: Desplazamiento aéreo Bogotá - Puerto Carreño (La única aerolínea comercial que llega a la zona es SATENA), cuyo tiempo aproximado de vuelo es de una hora y media. Ruta 2: Desplazamiento terrestre Bogotá - Puerto Gaitán (Meta) y de allí por vía fluvial a través del río Meta hasta Puerto Carreño. Existe una línea comercial fluvial cuyos cupos deben ser comprados con un día de anterioridad en Puerto Gaitán. El tiempo aproximado de viaje es de 12 horas y el servicio se presta en temporada de aguas altas. Ruta 3: Desplazamiento por vía terrestre Bogotá/ Villavicencio - Puerto Carreño, en la línea comercial de flota la Macarena. El pasaje debe ser comprado con anterioridad y el servicio se presta sólo en temporada de verano, el tiempo aproximado de viaje es de dos días". Tomado del sitio web: https://viajerosdelorinoco.com/contactenos/como-llegar-a-carreno/.
} 


\begin{tabular}{|c|c|c|c|}
\hline & & & $\begin{array}{l}\text { los estados de Amazonas } \\
\text { y Bolívar. }\end{array}$ \\
\hline $\begin{array}{l}\text { Frente Rafael Blanco } \\
\text { Flores del ELN }\end{array}$ & $\begin{array}{l}\text { Controla y regula el } \\
\text { paso de personas y } \\
\text { el ingreso y } \\
\text { comercialización de } \\
\text { víveres y gasolina } \\
\text { desde Venezuela } \\
\text { por medio del cobro } \\
\text { de cuotas y desde } \\
2017 \text { se le atribuye } \\
\text { la apropiación de } \\
\text { minerales } \\
\text { explotados en el sur } \\
\text { del vecino país y } \\
\text { que luego son } \\
\text { ingresados y } \\
\text { transados en } \\
\text { Colombia. La } \\
\text { presencia del ELN } \\
\text { en Venezuela es de } \\
\text { vieja data } \\
\text { especialmente en } \\
\text { los estados de } \\
\text { Apure y Bolívar, la } \\
\text { novedad radica en } \\
\text { que se esta } \\
\text { haciendo más } \\
\text { evidente en Puerto } \\
\text { Páez, Puerto } \\
\text { Ayacucho y San } \\
\text { Fernando de } \\
\text { Atapabo, todas } \\
\text { poblaciones } \\
\text { venezolanas } \\
\text { ubicadas en el } \\
\text { Estado de } \\
\text { Amazonas, sobre } \\
\text { los márgenes del } \\
\text { río Orinoco. }\end{array}$ & $\begin{array}{l}\text { El Bloque } \\
\text { Libertadores del } \\
\text { Vichada (BLV) }\end{array}$ & $\begin{array}{l}\text { Se ubica en los } \\
\text { siguientes municipios del } \\
\text { Vichada: Cumaribo, La } \\
\text { Primavera, Puerto Carreño } \\
\text { y Santa Rosalía. Dentro } \\
\text { del entramado criminal de } \\
\text { la región, el BLV solo } \\
\text { ejerce control en puntos } \\
\text { específicos de la } \\
\text { estratégica ruta del } \\
\text { narcotráfico que se inicia } \\
\text { en la margen norte del } \\
\text { departamento del Meta en } \\
\text { el municipio de Puerto } \\
\text { López y va hasta Puerto } \\
\text { Carreño (Vichada) en la } \\
\text { frontera con Venezuela. Lo } \\
\text { que evidencia que esta } \\
\text { organización armada } \\
\text { funciona como un } \\
\text { dinamizador de la } \\
\text { economía del narcotráfico } \\
\text { con algunas interacciones } \\
\text { de carácter transnacional. }\end{array}$ \\
\hline
\end{tabular}

Fuente: elaborado por los autores con base en: ALVAREZ, E., PARDO, D., \& CAJIAO, A. (2018); ALVAREZ, E; LLORENTE, M; CAJIAO, A \& GARZÓN, J. (2017); Observatorio del Programa Presidencial de DH y DIH. Diagnostico departamental del Vichada. Bogotá: Vicepresidencia de la Republica. 2008.

A partir de la sistematización expuesta en la Tabla 1, se percibe que, estos departamentos hacen presencia activa las disidencias de los Frentes 1, 16 y Acacio Medina, de las desmovilizadas FARC-EP, el Frente Rafael Blanco Flórez del ELN y el Grupo Armado Organizado (GAO) Bloque Libertadores del Vichada. En este artículo se entiende como disidencias a todas aquellas unidades y estructuras de las entonces 
FARC-EP que por múltiples razones se mantuvieron en armas al no participar o alejarse del proceso de negociación que esta organización armada realizó con el gobierno colombiano y que dio paso a su desarme, desmovilización y transformación en partido político ${ }^{5}$.

Las disidencias de los Frentes 16, Acacio Medina y 1 (Armando Ríos) son grupos que operan en los mismos territorios que los frentes de las entonces FARCEP y se dedican a las mismas actividades económicas y, según Álvarez, Pardo y Cajiao (2018), cuentan con una coordinación operativa.

La disidencia del Frente 1 controla el paso por el río Vaupés hacia Brasil, "y rechazan los acuerdos de sustitución voluntaria que han realizado los campesinos hasta ahora con el gobierno nacional" (OBSERVATORIO DEL PROGRAMA PRESIDENCIAL DE DH Y DIH, 2008, p. 5). Según Álvarez, Pardo y Cajiao (2018) esta disidencia del Frente 1 no sólo controla y regula la compra y venta de hoja de coca, sino también el procesamiento de la misma y su salida por las vías fluviales de la región, por medio de la coordinación de acciones con otros grupos disidentes o por su propia gestión hasta el comprador final.

En cuanto a la disidencia del Frente Acacio Medina, esta mantiene rutas de movilidad que van desde Barranco Mina en el Guainía y Cumaribo en el Vichada hasta el río Orinoco, pero con mayor presencia y actividad en Venezuela por el río Venturi hasta los márgenes del Arco Minero del Orinoco en el estado de Amazonas ${ }^{6}$. Se sospecha que uno de los líderes de esta disidencia, "John 40", se encuentra protegido en Venezuela por la fuerza pública de ese país a cambio del pago de sobornos. Es así como "Julián Chollo" y un indeterminado número de colombianos y venezolanos, que han tomado el control de las minas de oro ubicadas en el Parque Natural

\footnotetext{
${ }^{5}$ Sobre el debate conceptual en torno a las disidencias y reincidencias, véase Álvarez, Pardo y Cajiao (2018).

6 "La Zona de Desarrollo Estratégico Nacional Arco Minero del Orinoco (AMO) cuenta con una superficie de 111.843 kilómetros cuadrados, divididos en cuatro áreas de explotación y exploración: el Área 1 $(24.680,11 \mathrm{Kms} 2)$ que limita al occidente con el río Cuchivero, donde predominan los minerales bauxita, coltán, tierras raras y diamantes; el Área $2(17.246,16 \mathrm{Kms} 2)$ entre el río Cuchivero y el río Aro, en la que predominan hierro y oro; el Área $3(29.730,37 \mathrm{Kms} 2)$ que se encuentra entre el río Aro hasta y el límite Este del AMO, en donde predominan bauxita, cobre, caolín dolomita; y el Área 4, que abarca la Reserva Forestal Sierra de Imataca $(40.149,69 \mathrm{Km} 2)$ donde hay oro, bauxita, cobre, caolín y dolomita" (PRESIDENCIA DE LA REPÚBLICA BOLIVARIANA DE VENEZUELA, 2016 apud ÁLVAREZ; PARDO; CAJIAO, 2018).
} 
Yapacana. Esta disidencia ha usado como ruta de penetración al territorio venezolano el paso fronterizo de San Fernando de Atabapo, remontando el río Ventuari, hacia el Parque Yapacana y hasta la zona de San Juan de Manapiare, que se une con la Serranía Guanay en los límites de los estados de Amazonas y Bolívar (ÁLVAREZ; PARDO; CAJIAO, 2018).

El ELN hace presencia en el territorio por medio del Frente Rafael Blanco Flores. La estructura armada recibe el nombre del abatido segundo comandante del Frente José David Suarez, muerto en combates con el Ejército Nacional en zona rural de Tame, Arauca, en mayo de 2013. Por medio de esta estructura armada adscrita al Frente de Guerra Oriental, el ELN inicia un proceso de expansión territorial desde 2016 aprovechando los vacíos dejados por la desmovilización y desarme del Bloque Oriental de las FARC-EP. En este sentido, la Defensoría del Pueblo a través de su Sistema de Alertas Tempranas sostiene que la ruta de penetración del Vichada se inició por Puerto Carreño y llegó hasta el municipio de Cumaribo en el centro del departamento, donde iniciaron la regulación del narcotráfico y el contrabando. (idem)

Según Garzón, Cajiao y Cuesta (2018), el ELN controla y regula el paso de personas y el ingreso y comercialización de víveres y gasolina desde Venezuela por medio del cobro de cuotas y desde 2017 se le atribuye la apropiación de minerales explotados en el sur del vecino país y que luego son ingresados y transados en Colombia. Estos autores también sostienen que la presencia del ELN en Venezuela es de vieja data especialmente en los estados de Apure y Bolívar. La novedad radica en que se está haciendo más evidente en Puerto Páez, Puerto Ayacucho y San Fernando de Atapabo, todas poblaciones venezolanas ubicadas en el Estado de Amazonas, sobre los márgenes del río Orinoco.

El Bloque Libertadores del Vichada nace después de la desmovilización de las AUC en el año 2006. Según Álvarez, Llorente, Cajiao y Garzón (2017), el Bloque Libertadores del Vichada (BLV) se ubica en los siguientes ocho municipios: Mapiripán, Puerto Gaitán, Puerto López, Villavicencio (departamento del Meta), Cumaribo, La Primavera, Puerto Carreño y Santa Rosalía (departamento del Vichada). Dentro del entramado criminal de la región, el BLV solo ejerce control en puntos específicos de la estratégica ruta del narcotráfico que se inicia en la margen norte del departamento 
del Meta en el municipio de Puerto López y va hasta Puerto Carreño (Vichada) en la frontera con Venezuela. Esto evidencia que esta organización armada funciona como un puente y un dinamizador de las economías ilegales del narcotráfico con algunas interacciones de carácter transnacional.

Tabla 2 - Presencia y gobernanza de los grupos armados no estatales em la frontera sur entre Colombia y Venezuela

\begin{tabular}{|c|c|c|c|c|}
\hline $\begin{array}{l}\text { Grupo } \\
\text { Armado } \\
\text { llegal }\end{array}$ & $\begin{array}{l}\text { Repertorio de } \\
\text { violencia }\end{array}$ & $\begin{array}{l}\text { Coordinación } \\
\text { con otros } \\
\text { Grupos } \\
\text { Armados }\end{array}$ & $\begin{array}{l}\text { Relación con } \\
\text { la población }\end{array}$ & $\begin{array}{l}\text { Economía de } \\
\text { Guerra }\end{array}$ \\
\hline $\begin{array}{l}\text { Conformados } \\
\text { por } \\
\text { exintegrantes } \\
\text { de los Frentes } \\
1 \text { y } 7 \\
\text { (Guaviare, } \\
\text { Guainía, } \\
\text { Vaupes). }\end{array}$ & $\begin{array}{l}\text { Emboscadas, } \\
\text { amenazas, } \\
\text { retén ilegal, } \\
\text { reclutamiento } \\
\text { forzado, } \\
\text { secuestro, } \\
\text { activación de } \\
\text { artefacto } \\
\text { explosivo, } \\
\text { ataque a } \\
\text { bienes } \\
\text { comerciales, } \\
\text { extorsión, } \\
\text { ataque a } \\
\text { personal } \\
\text { militar/ ataque } \\
\text { francotirador, } \\
\text { homicidios, } \\
\text { ataque a } \\
\text { infraestructura } \\
\text { energética y } \\
\text { hostigamiento }\end{array}$ & $\begin{array}{l}\text { Con las } \\
\text { disidencias de } \\
\text { los Frentes } 7, \\
16 \text { y Acacio } \\
\text { Medina. }\end{array}$ & $\begin{array}{l}\text { Acciones } \\
\text { predatorias y } \\
\text { de control, en } \\
\text { especial hacia } \\
\text { comerciantes y } \\
\text { pescadores. } \\
\text { No se observa } \\
\text { trabajo político } \\
\text { de masas, } \\
\text { aunque sí se } \\
\text { presentan } \\
\text { como } \\
\text { protectores de } \\
\text { comunidades } \\
\text { cocaleras ante } \\
\text { riesgos de la } \\
\text { erradicación } \\
\text { forzada. }\end{array}$ & $\begin{array}{l}\text { Regulación de } \\
\text { la compra y } \\
\text { venta de hoja y } \\
\text { pasta de coca. } \\
\text { Procesamiento } \\
\text { y producción de } \\
\text { cocaína, } \\
\text { extorsión, } \\
\text { secuestros y } \\
\text { tala ilegal de } \\
\text { madera. }\end{array}$ \\
\hline $\begin{array}{l}\text { Exmiembros } \\
\text { del Frente 16, } \\
\text { ubicados } \\
\text { entre Vichada } \\
\text { y Guainía. } \\
\text { Exmiembros } \\
\text { del Frente } \\
\text { Acacio } \\
\text { Medina } \\
\text { localizados en } \\
\text { la frontera con } \\
\text { Venezuela y } \\
\text { en el estado } \\
\text { de Amazonas. }\end{array}$ & $\begin{array}{l}\text { Amenazas, } \\
\text { reclutamiento } \\
\text { forzado, } \\
\text { secuestros, } \\
\text { hostigamientos } \\
\text { y combates con } \\
\text { la fuerza } \\
\text { pública, } \\
\text { desplazamiento } \\
\text { forzado, } \\
\text { reuniones con } \\
\text { fines políticos y } \\
\text { extorsivos }\end{array}$ & $\begin{array}{l}\text { Aparente } \\
\text { coordinación } \\
\text { entre las } \\
\text { disidencias de } \\
\text { los Frentes } 16 \\
\text { y Acacio } \\
\text { Medina para el } \\
\text { control de } \\
\text { zonas mineras } \\
\text { en Vichada y } \\
\text { Guayana } \\
\text { venezolana. } \\
\text { Posible } \\
\text { utilización o } \\
\text { recambio de } \\
\text { brazaletes del } \\
\text { ELN en }\end{array}$ & $\begin{array}{l}\text { Situación de } \\
\text { vulnerabilidad, } \\
\text { especialmente, } \\
\text { para territorios } \\
\text { y comunidades } \\
\text { indígenas. }\end{array}$ & $\begin{array}{l}\text { Procesamiento } \\
\text { y tráfico de } \\
\text { estupefacientes, } \\
\text { minería ilegal y } \\
\text { extorsión. }\end{array}$ \\
\hline
\end{tabular}




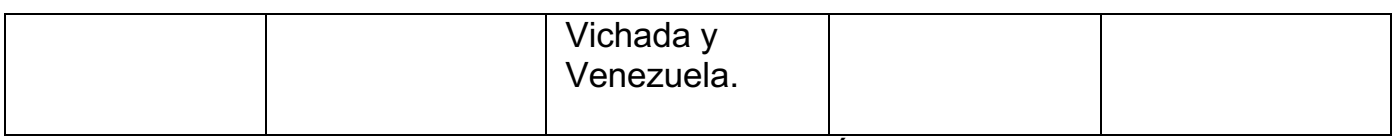

Fuente: elaborado por los autores con base en: Álvarez, Pardo y Cajiao (2018).

Con base en la consolidación desarrollada en la Tabla 2, se percibe que, poco a poco, los grupos disidentes de las FARC-EP se acomodaron en los departamentos fronterizos con Venezuela, y, por medio de distintos acuerdos de cooperación con otros actores armados no estatales, pudieron beneficiarse de recursos naturales o actividades relativas al tráfico de drogas, y ejercen la violencia de diferentes formas, a depender de la relación establecida con la población local.

Amenazas, reclutamiento forzado, secuestros y extorsión son algunas de las prácticas más incidentes para el uso de la violencia como manutención del control local. Además, los campesinos, productores de coca especialmente, pescadores, pequeños comerciantes e indígenas son el principal blanco de la acción de los grupos que operan en esta región.

Con este contexto, se puede afirmar que esta zona de la frontera se configura como un espacio de gobernanza híbrida, con fuerte presencia de actores armados no estatales, donde las sociedades de los Estados que no controlan el monopolio de la violencia tienden a diluirse y ser ocupadas por estos actores. En estos casos, la principal motivación de la acción violenta, pero no la única, es de tipo económico y de control social y territorial. En este marco, toda adquisición de bienes o servicios locales se basa en la violencia o en la amenaza real de su uso. Los actores armados no estatales, que son la base central de este sistema, combinan la apropiación violenta con la oferta de bienes y servicios públicos. Los mercados de la violencia tienen sus orígenes dentro de conflictos armados con motivaciones de tipo no económico, pero al fin la violencia se termina configurando como un eficiente medio de ampliar ganancias.

Al retomar los patrones de cooperación entre actores armados no estatales, de Phil Williams (2005), la dimensión del (i) tiempo parece caminar para cooperaciones sin tiempo definido, a medida que la operación se mantenga lucrativa y exitosa para dichos grupos; el patrón del (ii) tipo de actividad se presenta como parcerías dentro del mismo tipo de actividad, como la cadena de producción, procesamiento y venta de 
drogas, extracción de mineros, o incluso la actividad de extorsión (generalmente de pequeño comercio y campesinado); y, por fin, el (iii) nivel de cooperación parece estar entre ocasional y continuo, pero con presencia de disputas y debilidades en esta cooperación, lo que se demuestra por las periódicas explosiones de violencia como demostración de fuerza en la región.

Cuanto, a las categorías de interacción entre los actores armados no estatales, presentados por Annete Idler (2012), es posible afirmar que en la región van desde el (i) combate violento (periódico) a (ii) subcontratos, (iii) relaciones logísticas complementarias y (iv) alianzas estratégicas.

En el caso de la zona sur, se debe hacer una subdivisión, ya que en el departamento de Arauca, a pesar de la presencia de cultivos ilícitos, se aprecia un avanzado proceso de depredación de rentas legales, que se materializa en la extorsión por parte del ELN de las empresas petroleras asentadas en el territorio ${ }^{7}$. Además, Arauca se configura como la puerta de entrada al territorio venezolano, país en que el ELN ha establecido parte de su comandancia estratégica y, a través del Estado Apure, ha llegado hasta el Arco Minero del Orinoco, subregión en la que regula y captura rentas provenientes de la minería legal e ilegal.

En los casos de Vichada y Guainía, se observa que en torno a la administración de rentas ilícitas se conformó una gobernanza de la ilegalidad, ya que las estructuras criminales presentes en dicho territorio (tres grupos disidentes de las extintas FARC$E P$, un frente del ELN y el Bloque Libertadores del Vichada), no solo parecen coordinar

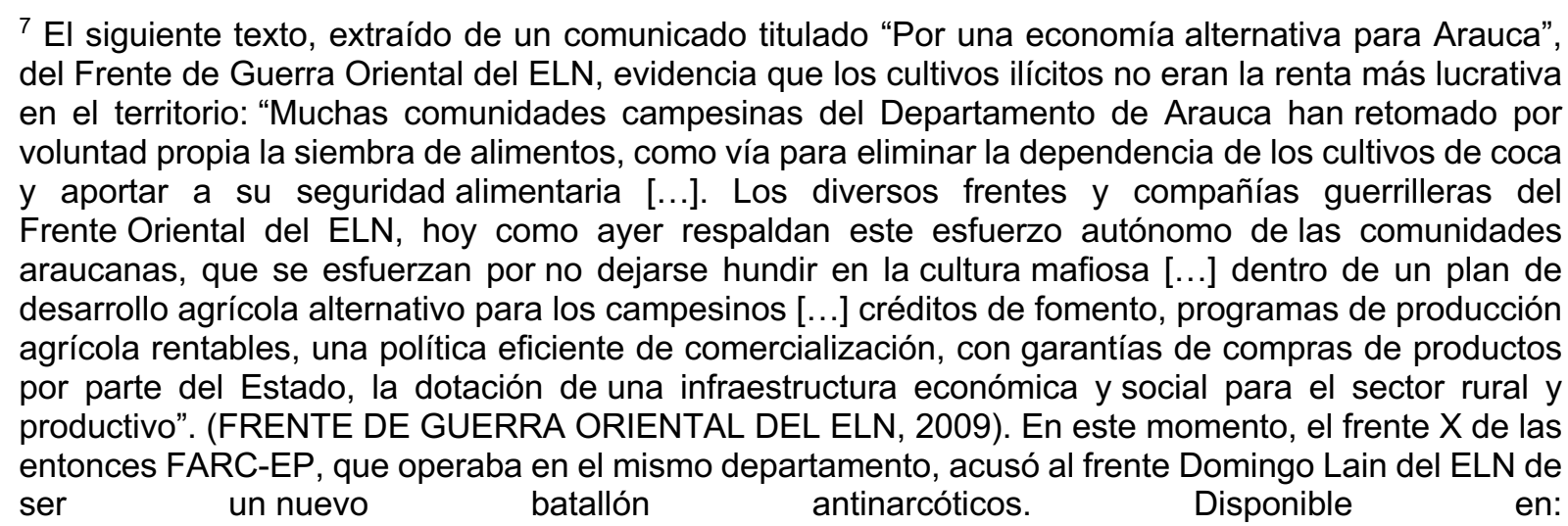
http://www.redcolombia.org/oscar/varie/Comunicato ELN Arauca es.pdf. Acceso en 21.03.2019. 
su actividad delincuencial, sino que también ejercen las funciones duras del Estado, tales como brindar seguridad, administrar justicia, regular la economía local y generar empleo.

\section{CONCLUSIONES}

Este artículo tuvo como objetivo reflexionar sobre la situación de seguridad en la zona sur de la frontera entre Colombia y Venezuela, ubicada en el territorio amazónico de ambos Estados. Se revisaron las dinámicas producidas por la presencia de actores armados no estatales en los departamentos colombianos de Arauca, Vichada y Guainía. Teniendo como contexto la baja presencia estatal en esta subregión colombiana, así como los mecanismos informales de gobernanza criminal generados por los grupos armados no estatales, las conclusiones fueron que, en general, los grupos disidentes que se formaron durante y después de las negociaciones de los Acuerdos de Paz con las Fuerzas Armadas Revolucionarias de Colombia - Ejército del Pueblo (FARC-EP) han logrado coordinar, con empleo de violencia, su actividad criminal con otros actores armados.

La compleja situación de seguridad presente en el lado colombiano de la frontera sur colombo-venezolana se debe, entre otras cosas, a la tendencia de disposición centralista del Estado colombiano y a su poblamiento, lo que ha hecho que en sus zonas de frontera este tenga una débil presencia o esté totalmente ausente. Esta situación ha posibilitado la aparición de grupos armados no estatales que por medio de la violencia o de la amenaza real de su uso construyen órdenes sociales que permiten la convivencia en esos territorios.

Ninguna política pública o medida institucional que se asuma desde el lado colombiano tendiente al combate y disminución de las rentas ilícitas y la presencia de actores armados no estatales tendrá efectos positivos si no está acompañada de una política efectiva de reformulación estructural de las condiciones económicas, sociales y de seguridad de las poblaciones locales.

Esta es una región que puede considerarse conceptualmente un área no gobernada, sobre todo por sus características estructurales, y, por este motivo, las acciones políticas del Estado deben llevar en cuenta esta necesidad de cambio 
estructural. Por eso, la frontera sur puede considerarse una Zona Estratégica para los Tránsitos llícitos (ZEETI).

Por la complejidad de las dinámicas criminales presentes en ella y la heterogeneidad de su geografía y asentamientos humanos, la frontera colombovenezolana debe dejar de percibirse como un todo lineal y continuo. De ahí que en este trabajo se analice la zona sur de la frontera entre Colombia y Venezuela

En esta subregión, se observa que los actores armados no estatales crearon relaciones económicas y de ocupación territorial profundas, con generación de gobernanza y periódicas explosiones de violencia, cuando hay puntos de desacuerdo entre estos grupos.

Cuanto a los patrones de cooperación entre actores armados no estatales, en la dimensión temporal, se camina para cooperaciones sin tiempo definido, a medida que la operación se mantenga lucrativa y exitosa para dichos grupos. Cuanto al tipo de cooperación, se presentan como parcerías dentro del mismo tipo de actividad, como la cadena de producción, procesamiento y venta de drogas, extracción de mineros, o incluso la actividad de extorsión (generalmente de pequeño comercio y campesinado). Por fin, el nivel de cooperación parece estar entre ocasional y continuo, pero con presencia de disputas y debilidades en esta cooperación, lo que se demuestra por las periódicas explosiones de violencia como demostración de fuerza en la región, por parte de estes actores.

Finalmente, las condiciones débiles del Estado, y de estas regiones en específico, generan este status de vulnerabilidad/ fragilidad altamente rentable y operacional para estos grupos. El Acuerdo de Paz, en este sentido, no fue capaz de disminuir la presencia de grupos armados no estatales en la región, al contrario, estos se pulverizaron y se difundieron, y, a su vez, siguen expandiéndose por los países fronterizos, como Venezuela y Brasil.

Se retoma, de esa manera, el paradigma de la Zona de Paz en América del Sur para un status paradójico, en que la ausencia de conflictos "estadocéntricos" no significan la construcción cada vez más amplia y profunda de una Paz Positiva, sino a una Zona de No Guerra en la región, con fuerte actuación de actores armados no estatales, los cuales generan explosiones de violencia y ejercen gobernanza en las 
regiones donde actúan. Hay, por lo tanto, en estos espacios, una gobernanza híbrida, formada por una confluencia de actores estatales, actores no estatales y grupos vulnerables.

\section{Referencias Bibliográficas}

ALVAREZ, E.; PARDO, D.; CAJIAO, A. Trayectorias y dinámicas territoriales de las disidencias de las FARC. Serie informes n. 30. Bogotá: Fundación Ideas Para la Paz, 2018.

ALVAREZ, E.; LLORENTE, M.; CAJIAO, A.; GARZÓN, J. Crimen organizado y saboteadores armados en tiempos de transición. Serie informes n. 27. Bogotá: Fundación Ideas Para la Paz, 2017.

ÁVILA, A. La frontera caliente entre Colombia y Venezuela. Bogotá: Nomo Impressores, 2012.

BARTOLOMÉ, M. ¿Áreas sin ley o zonas grises? Análisis de tres casos en la zona noroeste de América del Sur. 2003. Disponible en: http://www.geocities.ws/mcbartolome/eee2003.pdf. Acceso en: 11.10.2019.

BATTAGLINO, J. The coexistence of peace and conflict in South America toward a new conceptualization of types of peace. Revista Brasileira de Política Internacional, v. 55, n. 2, p. 131-151, 2012.

BUZAN, B.; WEAVER, O.; DE WILDE, J. Security: A new framework for analysis. Boulder, Co.: Lynne Rienner, 1998.

BUZAN, B.; WEAVER, O. Regions and Powers: The Structure of International Security. New York: Cambridge University Press, 2003.

BUZAN, B.; WEAVER, O. Macrosecuritisation and security constellations: reconsidering scale in securitisation theory. Review of International Studies, v. 35, n. 2, p. 253-276, 2009.

CIRINO, J. Las áreas sin ley en el hemisferio: una hipótesis de trabajo. 2002. Disponible en: https://www.resdal.org/Archivo/d000025b.htm. Acceso en: 11.10.2019.

CIRINO, J.; ELIZONDO, S. Áreas sin ley: orígenes del fenómeno y percepciones de amenaza. Buenos Aires: Center for Hemispheric Defense Studies, 2003.

CLUNAN, A. Ungoverned Spaces? The Need for Reevaluation. In: TRINKUNAS, H.; CLUNAN, A. Ungoverned Spaces. Alternatives for State Authority in an Era of Softened Sovereignty. Stanford: Stanford University Press, 2010. 
CUBIDES, F. Burocracias armadas: el problema de la organización en el entramado de las violencias colombianas. Bogotá: Grupo Editorial Norma, 2005.

DOMÍNGUEZ, J. International cooperation in Latin America: the design of regional institutions by slow accretion. In: AMITAV, A.; ALASTAIR, I. J. (Eds.). Crafting Cooperation: regional international institutions in comparative perspective. New York: Cambridge University Press, 2007.

EL ESPECTADOR. Planes secretos de las FARC. 14 de marzo de 2014. Disponible en: https://www.elespectador.com/noticias/judicial/planes-secretos-de-farc-articulo481027. Acceso en: 23.03.2019.

FRANÇOIS, M.; SUD, I. Promoting Stability and Development in Fragile and Failed States. Development Policy Review, v. 24, n. 2, p. 141-160, 2006.

FRENTE DE GUERRA ORIENTAL DEL ELN. Por una economía alternativa para Arauca. $2009 . \quad$ Disponible en: http://www.redcolombia.org/oscar/varie/Comunicato_ELN_Arauca_es.pdf. Acceso en 21.03.2019.

FUNDACIÓN IDEAS PARA LA PAZ. Dinámicas del Conflicto Armado y su Impacto Humanitario. Bogotá. 2014.

GOBERNACIÓN DEL VICHADA. Nuestro Departamento. 2017. Disponible en: http://www.vichada.gov.co/departamento/nuestro-departamento. Acceso en: 12 mar. 2019.

GOBERNACIÓN DEL GUAINÍA. Historia del Guainía. 2018. Disponible en: http://www.guainia.gov.co/departamento/historia-del-departamento-del-guainia. Acceso en: 21 mar. 2019.

GOVERNMENT ACCOUNTABILITY OFFICE. Drug Control. U.S. counternarcotics cooperation with Venezuela has declined. Washington, 2009. Disponible en: http://www.gao.gov/new.items/d09806.pdf. Acceso en: 11.10.2019.

HOLSTI, K. The State, War, and the State of War. Cambridge: Cambridge University Press, 1996.

IDLER, A. Exploring agreements of convenience made among violent non-state actors. Perspectives on Terrorism. v. 6, n. 4-5, p. 63-84, oct. 2012.

IDLER, A. Cocaine supply chain relationships in Colombia and their impact $\mathrm{n}$ citizen security: how does the Narco-broker come in? In: ANNUAL CONFERENCE OF THE INTERNATIONAL SOCIETY FOR THE STUDY OF DRUG POLICY, 7, 2013, Bogotá, Colombia. Conference Papers [...]. Bogotá, Co: ISSDP, mayo, 2013.

IDLER, A.; FOREST, J. Behavioral patterns among (violent) non-state actors: a study 
of complementary governance. Stability: International Journal of Security \& Development. v. 4, n.1, p. 1-19, 2015.

KACOWICZ, A. Zones of Peace in the Third World. South America in Comparative Perspective. Albany: State University of New York, 1998.

KACOWICZ, A. The impact of norms in international society: The Latin American experience, 1881-2001. Notre Dame: University of Notre Dame Press, 2005.

MARES, D. Violent Peace. New York: Columbia University Press, 2001.

MARES, D. Por que os latino-americanos continuam a se ameaçarem? O uso da força militar nas relações intra latino-americanos. Varia História, Belo Horizonte, v. 28, n. 48, p. 599-625, jul./dez. 2012.

MILLER, B. States, Nations, and the Great Powers. The Sources of Regional War and Peace. Cambridge: Cambridge University Press, 2007.

MERKE. F. Neither balance nor bandwagon: South American international society meets Brazil's rising power. International Politics. v. 52, n.2. 2015. p.178-192.

MOLANO-ROJAS, A.; SALAZAR, F. Fronteras: gobernanza, sensibilidad y vulnerabilidad. In: MOLANO-ROJAS, A. (Ed.). Fronteras en Colombia como zonas estratégicas: análisis y perspectivas. Bogotá: KAS / Instituto de Ciencia Política Hernán Echavarría Olózaga, 2016. p. 17-42.

OBSERVATORIO DEL PROGRAMA PRESIDENCIAL DE DH Y DIH. Diagnostico departamental del Cesar. Bogotá: Vicepresidencia de la Republica, 2009.

OBSERVATORIO DEL PROGRAMA PRESIDENCIAL DE DH Y DIH. Diagnostico departamental del Vichada. Bogotá: Vicepresidencia de la Republica, 2008.

O'DONNEL, G. On the State, Democratization and Some Conceptual Problems.

A Latin American view with glances at some post-communist countries. Working Paper n.192. 1992.

OELSNER, A. International Relations in Latin America: Peace and Security in the Southern Cone. London: Routledge, 2009.

OELSNER, A. Friendship, mutual trust and the evolution of regional peace in the international system. Critical review of international social and political philosophy, v. 10, n. 2, p. 257-279, 2007.

OFICINA DE LAS NACIONES UNIDAS CONTRA LA DROGA Y EL DELITO. Colombia. Monitoreo de territorios afectados por cultivos ilícitos 2017. Bogotá: Organización de las Naciones Unidas, 2018. 
PIMENTA, M. Do oráculo ao mosaico de vozes: elementos chave para a compreensão do cenário pós conflito colombiano. In: AYERBE, L. F. (Org.). Análise de conjuntura em relações internacionais. 1 ed. São Paulo: Cultura Acadêmica, 2016. p. 201-227.

PIMENTA, M. Zonas Estratégicas e Estruturais para os Trânsitos Ilícitos (ZEETI): desafios à zona de paz na américa do sul. 2016. 302 f. Tese (Doutorado) - Curso de Relações Internacionais, Unesp - Unicamp - Puc-Sp, São Paulo, 2016.

PIMENTA, M. Soberania fragmentada nas fronteiras amazônicas frente à crescente presença do narcotráfico: uma tragédia anunciada?. Perspectivas: Revista de Ciências Sociais, v. 50, p. 173-185, 2017.

PROGRAMA PRESIDENCIAL DE DDHH Y DIH. Diagnóstico Departamental Arauca 2003-2007. Bogotá. 2008

RABASA, A.;BORAZ, S.; CHALK, P.; CRAGIN, K.; KARASIK, T.; MORONEY, K.; O'BRIEN, K.; PETERS, J. Ungoverned territories: understanding and reducing terrorism risk. Santa Monica: RAND Corporation, 2007.

RODRIGUEZ, A.; DE LA PUENTE, M.; y TREJOS, L. Análisis de la frontera ColombiaVenezuela, 2219 kilómetros para la integración. Barranquilla: Editorial Universidad del Norte, 2018.

ROSENAU, J. N. Turbulence in World Politics. Princeton: Princeton University Press, 1990.

ROSENAU, J. N.; CZEMPIEL, E. Governance without government: order and change in world politics. Cambridge: Cambridge University Press, 1992.

TREJOS, L. El lado colombiano de la frontera colombo-brasilera: una aproximación desde la categoría de área sin ley. Estudios Fronterizos, v. 16, n. 31, p. 39-64, 2015.

TREJOS, L.; Badillo, R.; Irreño, Y. El caribe colombiano: entre la construcción de paz y la persistencia del conflicto. Jurídicas CUC, v. 15, n. 1, p. 9-46, 2019.

TREJOS, L.; MARTINEZ, F.; BADILLO, R. Aproximación a las dinámicas del conflicto armado en la ciudad de Barranquilla "Entre la marginalidad insurgente y el control paramilitar 1990-2006". Papel Político, v. 23, n. 2, p. 1-22, 2019.

TREJOS, L.; GUZMÁN, J. Clientelismo armado en el Caribe colombiano por medio de la Reconfiguración Cooptada del Estado. El caso del Bloque Norte de la Autodefensas Unidas de Colombia. Justicia, v. 23, n. 34, p. 555-578, 2018.

TICKNER, A.; GARCÍA, D.; ARREAZA, C. Actores violentos no estatales y narcotráfico en Colombia. In: MEJÍA, D.; GAVIRIA, A. Política antidrogas en Colombia. Bogotá: Ediciones Uniandes, 2011. 
VILLA, R.; PIMENTA, M. Violent non-State Actors and New Forms of Governance: Exploring the Colombian and Venezuelan Border Zone. Journal of Human Security, v. 15, n. 1, p. 6-18, 2019.

VILLA, R.; PIMENTA, M. A longa paz na América do Sul: Questionamentos às teses da paz negativa na região. Papel Político, v.21, n.2, p. 435-468, jul./dez. 2016.

WILLIAMS, P. Here be Dragons. Dangerous Spaces and International Security. In: TRINKUNAS, H.; CLUNAN, A. Ungoverned Spaces. Alternatives to the State Authority in an Era of Softened Sovereignty. Stanford: Stanford University Press, 2010.

WILLIAMS, P. Cooperación entre organizaciones criminales. In: BERDAL, M.; SERRANO, M. (Orgs.). Crímen Transnacional Organizado y seguridad internacional. Cambio y Continuidad. Guadalajara: Fondo de Cultura Económica, 2005.

Recebido em: 27/01/2020

Aprovado em: 28/09/2020 